\title{
EDUCAÇÃO, LINGUAGEM E PRODUÇÃO DO CONHECIMENTO
}

\author{
Jayme Ferreira BU EN O*
}

\section{Resumo}

0 texto resenha a produção mais relevante do núcleo de estudos Educação, Linguagem e Produção do Conhecimento do Curso de M estrado em Educação da Pontifícia U niversidadeC atólica do Paraná. Como foco principal, apresenta dados de pesquisa desenvolvida no Programa de Iniciação Científica PIBIC/CN Pq sobre a linguagem do professor no ensino médio, em escolas de Curitiba e Região M etropolitana. Ao comentar os dados, aponta divergências entre o modo de ver e de sentir a linguagem pelos alunos e pelos professores pesquisados. 0 s estudantes preferem que se faça uso de uma linguagem clara e dinâmica, adaptada à realidade da escola, enquanto os docentes, mais conservadores em sua postura, defendem o emprego de uma linguagem elaborada, mais próxima do padrão culto da língua. 0 texto trata ainda da responsabilidade e do cuidado que se deve ter com a linguagem em sala de aula, por tratar-se não somente de um meio de comunicação ou de transmissão de conteúdos, mas principalmente por constituir um eficiente recurso pedagógico para a construção de conhecimento.

Palavras-chave: educação, linguagem, pesquisa, linguagem docente, iniciação científica.

\section{Resumen}

El texto reseña la producción más expresiva del nucleo de estudios Educación, Lenguaje y Producción de Conocimiento del Curso de Posgraduación M estrado en Educación de la Pontificia U niversidad C atólica del Paraná, en Brasil. Presenta datos de investigación que se desenvolvió en el Programa de Iniciación Científica - PIBIC / CN Pq / M inisterio de la Educación sobre el lenguaje del profesor en el Bachillerato, en escuelas de Curitiba y al rededores. Al comentar los datos, apunta divergencias entre la manera de ver y de sentir el lenguaje por los alumnos y por los docentes investigados. M ientras los estudiantes expresan la preferencia por un lenguajeclaro y dinámico, deacuerdo

* D outor em Letras, é professor-orientador no Curso de M estrado em Educação da PU CPR. 
con la realidad dela escuela; los docentes, más conservadores, defienden el uso de un lenguaje elaborado, más próximo al padrón culto de la lengua. El texto se refiere aún a la responsabilidad y al cuidado que hay quetener con el lenguaje en clase, por tratarse no sólo de un medio de comunicación o de transmisión de contenidos, sino principalmente por constituir eficiente recurso pedagógico para la construcción de conocimiento.

Palavras-llave: educación, lingueje, investigación, linguejedocente, iniciación científica

\section{Introdução}

O salunos do Programa deM estrado em Educação daPU CPR têm a oportunidade, epodesedizer também a sorte, decontarem no currículo de seu curso com disciplinas complementares, como, por exemplo, Linguagem e Educação e Leitura e Educação, a primeira dirigida mais especificamente para a produção do texto científico e, a segunda, para a formação do leitor. Ambas são disciplinas optativas, pertencentes à Linha de Pesquisa Teoria e Prática Pedagógica na Educação Superior. De certo modo, pelos temas enfocados, podese considerar que essas disciplinas, em conjunto, constituem uma subdivisão daquela Linha, por formarem um campo próprio de estudos, aqui designado Educação, Linguagem e Produção do Conhecimento. Integrando aquela Linha de Pesquisa, vem complementála no sentido de fornecer-Ihe elementos teóricos e práticos para a elaboração de trabal ho científico na área da Educação interligada à área dos Estudos da Linguagem .

$N$ ão se pode desconhecer a íntima ligação da Lingüística com a Educação. A linguagem, objeto da Lingüística, perpassa todos os campos do conhecimento humano. É por meio dela queo pesquisador, seja em queárea for, planeja, organiza, desenvolve sua pesquisa ea transmiteà comunidade científica e ao público em geral. É sob a forma de linguagem que o conhecimento se constrói e se difunde. Para BART H ES (1977), "perceber o que significa uma substância é, fatalmente, recorrer ao recorte da língua: sentido só existequando denominado, eo mundo dos significados não é outro senão o da linguagem" (p.12).

N essa linha de pensamento, ou seja, da consciência da importância da linguagem e de se acreditar na impossibilidade de se fazer ciência sem ela, é que há algum tempo foi proposta para o M estrado em Educação a disciplina Linguagem e Educação. M ais tarde, como forma de se complementarem os objetivos e se alargar 0 âmbito das pesquisas no Programa, propôs-se a disciplina Leitura eEducação. Com o aperfeiçoamento do currículo do Curso e para se explicitar melhor o teor dessas 
disciplinas, éque se passou a falar em Educação, Linguagem e Produção do Conhe cimento, como novo campo de estudos. D essa forma, conseguia-se privilegiar Educação, queéo núcleo do Curso; registrava-se a Linguagem como o meio imprescindível pelo qual se faz ciência; e, pelo acréscimo de Produção do Conhecimento, expressava-se a finalidade a que essa subdivisão se propõe: contribuir para a ampliação das pesquisas educacionais no Curso de M estrado em Educação. Participam desse campo de estudos os professores doutores do Programa de Pós-Graduação em Educação PU CPR, JaymeFerreira Bueno e M arta M orais da Costa.

A disciplina Linguagem eEducação, embora relativamenterecenteno currículo do Curso, já pode apresentar uma produção considerável, tanto quantitativamente como pela qualidadedos estudos quegerou. N essecampo deestudos que envolve o inter-relacionamento da Educação com a Linguagem, foram orientadas e defendidas dissertações de mestrado, acompanhadas a elaboração e a aprovação de projetos de pesquisa, publicados artigos e foi apresentado relatório de iniciação à pesquisa científica.

\section{A) dissertações de mestrado:}

1. - - 0 ensino da língua portuguesa com o conhecimento do latim: uma análise dos fatores de textualidade em livros didáticos, de Grace dos Anjos Freire Bandeira, defendida em 1996. 0 estudo faz a análise de livros didáticos do ensino fundamental, distinguindo os exercícios de língua dos exercícios de gramática que esses livros apresentam. Constata lacunas semânticas na abordagem dos conteúdos gramaticaise lingüísticos, o queo estudo atribui ao desconhecimento da língual latina por partedos autores desses livros. Ressalta a necessidade de se recorrer ao conhecimento do latim, como um saber de apoio ao estudo e ao ensino da língua portuguesa.

2. - 0 ensino com pesquisa ea produção do texto universitário. U m estudo da coesão e da coerência textual, de Ana M aria de Barros Küster, defendida em 1998. A dissertação apóiz-se na Lingüística Textual e enfoca a coesão e a coerência como os dois principais elementos da textualidade. A pesquisa feita junto ao Curso de Fonoaudiologia da PU CPR apresenta estratégias de aperfeççoamento da produção do texto universitário. Para tanto, a autora valeu-se do ensino com pesquisa e do "aprender a aprender", como metodologias do ensinar e do aprender.

3. - - A prática pedagógica e a língua inglesa na formação universitária do profissional de Relações Públicas, de M aria Teresa M arins Freire, também defendida em 1998. 0 trabalho tevepor finalidadedemonstrar como o conhecimento do inglês pode contribuir para a adequada formação universitária do estudante e do futuro profissional de Relações Públicas. A pesquisa, que foi desenvolvida no Curso de Comunicação Social da PU CPR, propõe uma prática pedagógica fundamentada no paradigma interacionista sociocultural ea educação pela pesquisa. 
4. a - A prática pedagógica e a língua inglesa na formação universitária do profissional de Relações Públicas, de M ara Christina Vilas-Boas, defendida em 1999. Embora o foco principal do estudo seja a melhoria na ação docente e discente, a autora embasa asua pesquisa no conceito de ação edeintenção, segundo RICO EUR (1988). Esse autor destaca a importância do jogo da linguagem, quando se responde a perguntas, como "o quevai fazer?", "por que o faz?". N a ação pedagógica, o importante éa forma como o professor comunica ao aluno o queele propõe para sefazer e por que ele deseja que se faça. É o problema da comunicação que se coloca.

5. - - A leitura e o ensino com pesquisa no curso superior: uma proposta de aprender a aprender, de Ilze Salete Chiarello, defendida em 2000. A dissertação se volta principalmente para o problema da leitura. Segundo o estudo, a leitura, além de fundamental para o estudo com pesquisa, contribui para a formação do sujeito crítiCo, reflexivo e criativo. Conceitua-se 0 ato de ler na sua dimensão ampla e se refereà contribuição da leitura para a metodologia do "aprender a aprender". Propõe um plano de intervenção com o objetivo de modificar uma prática tradicional, transformando-a em uma prática inovadora. D essa forma, pode-seinstigar a leitura, a pesquisa e o pensar crítico.

6. - - Arte educação na produção detexto crítico ecriativo no ensino superior, de Luciana Bracarense Costa Fernandez, defendida em 2001. 0 objetivo principal do trabalho érefletir sobrea criticidadee a criatividadena produção detextos universitá rios. A autora defendeque os textos produzidos pelos alunos universitários, em tempos de "fim das certezas" (PRIG O GIN E, 1996), devam desenvolver aspectos críticos edecriatividadee, portanto, devem contemplar o pensamento eo sentimento. Como apoio teórico para a construção de textos, visando aos aspectos da criticidade foram enfocadas a coerência, a coesão e a reflexão sobre a realidade; para a criatividade, foi explorada principalmente a metáfora.

7.a - A prática pedagógica inovadora ea poesia como um elemento articulador no ensino da língua portuguesa no Curso de Pedagogia, de Ivana Aparecida Costa Cavalcanti, também defendida em 2001. A pesquisa investigou se a poesia como elemento articulador do ensino contribui paraatransformação da atividadede aprendizagem e para a aquisição do conhecimento em língua portuguesa. A autora busca com a pesquisa e com novas ações solidificar a idéia de que por meio da poesia se constrói conhecimentos em língua portuguesa com mais eficiência e criticidade, na busca da viabilização de maior autonomia do ser.

\section{B) Projetos de pesquisa}

1.․- - Como decorrência dos estudos desenvolvidos, os professores responsá veis por Educação, Linguagem eProdução do Conhecimento registraram Grupo de Pesquisa e vêm desenvolvendo o Projeto de Pesquisa A leitura docente na Pontifícia 
Universidade Católica do Paraná. 0 Projeto está sob a liderança da Prof.a D r.. M arta M orais daC ostaeco-liderança do Prof. D r. JaymeFerreiraBueno. Agrega professores do Curso deM estrado ede Cursos de G raduação etem a participação deumamonitora, aluna degraduação do C urso de Letras. 0 objetivo da pesquisaéfazer o mapeamento do gênero, do tipo deobras lidas, do gênero literário dessas obras, do tempo dedicado à leitura e outros dados sobre a leitura dos professores que lecionam na PU CPR.

2. - - Encontra-se aprovado e em desenvolvimento o Projeto de Pesquisa A nova proposta educacional da PU CPR: uma reflexão sobrea prática docentee os programasdeaprendizagem no Curso de LetrasPortuguês/Inglês, da mestranda Ester Framarim de Souza Silva, sob a orientação do Prof. D r. Jayme Ferreira Bueno. A pesquisa consiste numa reflexão sobre a prática docente e os Programas de Aprendizagem em Língua Inglesa a partir do Projeto Pedagógico da Universidade. 0 problema queestá sendo investigado é: Como a nova proposta educacional da PUCPR contida nas D iretrizes do Projeto Pedagógico contribuirá para a melhoria da prática docenteno ensino da Língua Inglesa na Instituição? A dissertação que resultará da pesquisa encontra-se em fase de elaboração, para submeter-se ao exame de qualificação e, posteriormente, à defesa no Curso de M estrado em Educação da PU CPR.

\section{C) Artigo publicado:}

No 2.ำ número de D iálogo educacional, revista do Programa de PósGraduação em Educação PU CPR, publicou-se 0 artigo "Produzir um bom texto: tarefa possível no ensino superior", de autoria do Prof. D r. Jayme Ferreira Bueno. $N$ ele, defende-se a necessidade e a possibilidade de se produzir textos de boa qualidade, principalmente no ensino superior. Para tanto, alerta-se para a necessidade de alguns conhecimentos lingüísticos e principalmente busca conscientizar sobre a importância desses conhecimentos. Recomenda-se ainda o emprego de determinadas técnicas de produção de texto.

\section{D) Relatório de iniciação à pesquisa científica.}

Aqui se encontra o foco principal deste texto. As dissertações com seus temas, os projetos de pesquisa com seus objetivos esua problemáticae o artigo publicado foram referidos de passagem como uma forma deseilustrarem as atividades que vêm sendo desenvolvidas no âmbito da educação com implicações do conhecimento específico da linguagem.

0 que se pretende, portanto, aqui, é relatar o trabalho também levado a efeito em decorrência da atuação nessa área, realizado no Curso de Graduação de Letras da PU CPR. Trata-se do Projeto de Pesquisa intitulado justamente Linguagem e Educação, que foi elaborado e desenvolvido sob a orientação do Prof. Dr. Jayme 
Ferreira Bueno, juntamente com a Bolsista do PIBIC e aluna do Curso de Letras D oraci Carvalho dos Santos Pimentel M achado. A pesquisa contou com a colaboração deduas outras alunas dessemesmo curso, Andressa M ara M oletaeM árcia Frantz.

\section{0 Projeto Linguagem e E ducação e sua metodologia}

0 Projeto foi desenvolvido no ano letivo de 1998 e teve o resumo do seu Relatório publicado pelo PIBIC em 1999. 0 objetivo geral da pesquisa foi "contribuir para a melhoria do ensino dalíngua portuguesa no ensino médio." N a realidade, constitui um trabalho de prospecção para se conhecer o pensamento de alunos e de professores dessenível de ensino, em escolas de Curitiba e da Região M etropolitana, sobre o emprego da linguagem em sala de aula.

Aos alunos foi perguntado por meio de questionário e de entrevistas sobre a preferência do tipo de linguagem que o professor deve empregar para melhor comunicar-se e para transmitir de forma mais proveitosa o conteúdo que está lecionando. Em termos pedagógicos, procurou-se levantar que linguagem o professor deve empregar nas suas aulas, para produzir conhecimento com seus alunos. No mesmo sentido e de modo muito parecido, foram questionados também os professores. As respostas e os pontos de vista, como de certo modo já se esperava, foram divergentes. Como se verá, alunos e professores entendem de forma diferenteque modalidade de linguagem deve ser empregada em sala de aula.

0 campo de pesquisa, como já se declarou, foram estabelecimentos de ensino médio de Curitiba e Região M etropolitana. A pesquisa realizou-se em dois estabelecimentosdaredepúblicadeensino, o Colégio Estadual Professor Francisco Zardo, de Curitiba, e o Colégio Estadual Costa Viana, de São José dos Pinhais. Foram pesquisados também alunos e professores de dois estabelecimentos particulares, 0 Colégio Bom Jesus e o Colégio N ossa Senhora M edianeira, ambos de Curitiba.

As perguntas apresentadas no questionário aos al unos foram as seguintes:

1. - - "Para você, como deveria ser a linguagem do professor?"

2. - - "Q uanto à linguagem do professor, como vocêgostaria que fossem as aulas?"

3. - - "Você prefere um professor que use uma linguagem comum ou uma linguagem melhor elaborada (uma linguagem tradicional)?"

Aos professores foram propostas as seguintes questões:

1. - . "Como professor, você considera que deve empregar em sala de aula uma linguagem comum ou uma linguagem melhor elaborada?"

2. - - "Para você, o professor deveadaptar-seou não à linguagem do aluno?" 
aluno?"

3. - - A seu parecer, a linguagem do professor influencia na aprendizagem do

Para os alunos, foram distribuídos 67 questionários, que foram respondidos na sua totalidade. Além das respostas dos questionários, foram recolhidos dados em entrevista com 20 alunos. 0 trabalho apresentado ao PIBIC foi ilustrado com gráficos. Aqui, porém, só se apresentam as porcentagens obtidas para cada questão.

\section{0 s dados da pesquisa}

\section{A) Respostas dos alunos}

O sdados obtidos com a pesquisa junto aos al unos, apresentados por questão, são os seguintes:

A 1.a - pergunta: "Para você, como deveria ser a linguagem do professor?" obteve os seguintes índices para as classificações propostas no questionário:

. clara- $56,5 \%$

. culta $-21,5 \%$

. espontânea - $11,5 \%$

- objetiva - $9,0 \%$

. agradável - 1,5\%

Como se pode observar, a nítida preferência, com mais da metade das manifestações, é para uma linguagem clara. Embora 0 adjetivo clara seja mais acessível ao estudante do ensino médio, registre-se que o qualificativo adequada seria mais apropriado, em termos lingüísticos, para se conceituar a linguagem que deve ser utilizada pelo professor em sala de aula.

A 2.. pergunta: "Q uanto à linguagem do professor, como vocêgostaria que fossem as aulas?" foi assim respondida pelos alunos:

. dinâmica - 47,1\%

. descontraída-25,5\%

. objetiva - 7,9\%

. igual a dos cursinhos - 7,9\%

. com recursos audiovisuais - $6,3 \%$

. sem mudanças - $5,2 \%$ 
A clara preferência por uma linguagem dinâmicae, portanto, não monótona, não cansativa, com quase metade das manifestações, mostra o anseio do estudante por aulas bem dadas por professores bem preparados e entusiasmados com suas atividades docentes. Essa preferência, aliadaao desejo deuma linguagem descontráda, explicita ainda mais a ten dência de dinamismo ede espontaneidade do professor em sala de aula. Ao aluno não agrada a imobilidade e o conservadorismo, mesmo em termos de linguagem.

A 3. pergunta: "Você prefere um professor que use uma linguagem comum ou uma linguagem melhor elaborada (uma linguagem tradicional)?" foi respondida desta forma:

. comum - $65,1 \%$

. elaborada- $24,2 \%$

. comum e depois elaborada - $6,1 \%$

- depende da matéria a ser aprendida - 4,5\%

M anifesta-se nas respostas a clara preferência, bem acima da metade dos pesquisados, por uma linguagem comum. Para os alunos do ensino médio, uma linguagem elaborada parece ser sinônimo de uma linguagem difícil, complicada. Estão sendo coerentes com o modo como responderam as duas perguntas anteriores, em que explicitavam o desejo de que o professor empregue uma linguagem clara (na 1.․ Pergunta) e dinâmica e descontraída (na 2. a Pergunta).

\section{B) Respostas dos professores}

Com referência às questões apresentadas aos professores, os dados obtidos, por pergunta, são os que seguem:

A 1.a - pergunta: "C omo professor, você considera que deve empregar em sala de aula uma linguagem comum ou melhor elaborada?" alcançou os seguintes índices:

. elaborada- $42,9 \%$

. comum - $35,7 \%$

. as duas linguagens $-21,4 \%$

Aqui jáseidentificauma primeira divergência entreosalunoseos professores sobre o modo de ver a linguagem que deve ser usada em sala de aula. Claramente, invertem-se as posições: para o aluno, uma linguagem mais comum que elaborada; para o professor, uma linguagem mais elaborada que comum. 
A 2. - - Pergunta: "Para você, o professor deve adaptar-se ou não à linguagem do aluno?" foi respondida com:

$$
\begin{aligned}
& \text {. sim }-52,4 \% \\
& \text { não - } 47,6 \%
\end{aligned}
$$

Embora tenha havido pequena vantagem para a resposta afirmativa, houve um grande equilíbrio no resultado. 0 s professores, em quase metade de suas respostas, manifestaram-se contrários a uma adaptação da sua linguagem ao contexto da linguagem do aluno. Portanto, quase metade dos docentes ainda resistea uma maior clareza e adequação da linguagem à realidade do aluno com que trabalha em sala de aula. É também uma forma de pensar edever alinguagem demodo diferentedaquele declarado pelos alunos.

A 3. - - Pergunta: "A seu parecer, a linguagem do professor influencia na aprendizagem do aluno?" teve a totalidade das respostas afirmativas:

$$
\begin{aligned}
& . \operatorname{sim}-100 \% \\
& \text {. não - 0\% }
\end{aligned}
$$

Essa demonstração unânime da crença de que a linguagem é mais do que um simples meio de comunicação ou detran smissão de conhecimento, mastambém e, principalmente, um recurso pedagógico eficiente alerta a nós professores sobre a responsabilidade e o cuidado que devemos ter com a linguagem, principalmente em sala deaula. 0 professor émuito o quefala. N a sua linguagem encontram-seelementos de sua personalidade. Já dizia Buffon, teórico e literato francês do século XVIII, no seu Di iscurso sobreo estilo: "lestyleestl'hommemême", ou seja, traduzindo, "estilo éo próprio homem." (LAN SON eTUFFRAU, 1953).

\section{Algumas considerações sobre a pesquisa.}

A pesquisa deixou claros al guns posicionamentos dos al unos e dos professores do ensino médio sobreo objeto investigado. Essas manifestações serão apresentadas na ordem em que a pesquisa foi desenvolvida e em que apareceu no Relatório apresentado ao PIBIC.

Com referência aos alunos, portanto, a primeira delas é que eles preferem uma linguagem clara, objetiva e espontânea. $N$ a realidade, eles desejam uma linguagem quetorne fácil a comunicação em sala de aula. Livros e falas com termos técni- 
cos ou muito especializados não são bem aceitos. É a busca por parte dos alunos de uma linguagem que venha ao encontro da realidade lingüística em que se encontram. D e um modo geral, esses alunos não possuem um vocabulário muito complexo, no sentido de umalinguagem formal segundo os parâmetrosda norma culta. Eles anseiam por uma linguagem adequada, pela qual possam melhor comunicar-se.

Além da linguagem clara, os alunos reivindicam uma aula dinâmica e descontraída e, portanto, sem muitaformalidade. G ostariam de quefossem reproduzidos em sala de aula o ambientee as formas de intercomunicação que normalmente vivenciam no seu dia-a-dia.

Essa preferência por uma adequação da linguagem ao seu modo de vida é fortemente reforçada pelas respostas dadas à 3. a Pergunta: desejam uma linguagem comum enão uma linguagem elaborada. Embora o Relatório apresentado ao PIBIC não tenha divulgado o índice, fez-se nele o comentário seguinte: "O utra observação com relação a esta mesma pergunta éque, em escolas particulares, os al unos preferem uma linguagem elaborada e, em escolas públicas, uma linguagem simples". Tal dife renciação realça o desejo de uma adequação da forma de linguagem ao meio cultural do qual provém o aluno.

Q uanto aosprofessores, ficou evidenciado quea maioria deles prefereuma linguagem elaborada, contrariamente ao desejo dos alunos. Justificam que se começarem com uma linguagem comum, dificilmente irão conseguir alcançar uma linguagem elaborada. Consideram que trabalhar em sala de aula com uma linguagem comum seria colaborar "com o processo de queda educacional e cultural pelo qual a sociedade está passando." Alguns professores semanifestaram, porém, pela utilização de ambas as linguagens, justificando, como se relatou ao PIBIC: "se fizerem uma linguagem muito simples, não alcançarão um aprofundamento na matéria, e se for uma linguagem muito técnica, 0 aprendizado torna-se difícil."

Alguns professores têm a consciência da necessidade de seadaptar à linguagem do aluno, como neste exemplo do Relatório: "éa linguagem deles, ou seja al go quese aproxime do meio em queelesvivem, trazendo exemplos próximosà realidade deles." O utros, porém, insistem que adaptar-se à linguagem do aluno seria estar "colaborando com o empobrecimento da língua dentro da sala de aula, que deveser um momento de aprendizado, e não o contrário."

Por fim, os professores têm a crença inabalável no seu poder de influenciar os alunos. Ao responderem a 3. - Pergunta, foram unânimes em declarar que a sua linguagem influenciana aprendizagem do aluno ( $100 \%$ responderam sim). Segundo eles, "é a partir da linguagem do professor que o aluno forma uma base para então construir a sua aprendizagem."

Pode-seobservar uma nítida diferença no modo de ver e de sentir a linguagem do ponto de vista dos alunos e dos professores. 0 s primeiros mais voltados para 
uma adequação da linguagem à realidade. 0 s segundos traduzem ainda uma forma mais conservadora de enfocar a linguagem como recurso para a produção de conhe cimento, como mostraram os dados obtidos pela pesquisa em escolas do ensino mé dio de Curitiba e Região M etropolitana.

\section{Considerações finais}

Como toda pesquisa qualitativa, esta mostra também uma realidade, queé a dicotomia da linguagem na escola. 0 professor, na maioria das vezes, emprega em sala de aula uma linguagem que não é, por assim dizer, compatível com a do aluno. Por outro lado, como poderia ele também utilizar apenas a linguagem do conhecimento e do uso comum do aluno? $\mathrm{N}$ ão seria realmente consolidar a "pobreza de linguagem" de quefalam muitos teóricos? Essa éuma questão complexa, dequenão nos cabe tratar no momento. Fiquemos, porém, com algumas observações:

1. a - 0 portuguêsnão éuma só língua. H ádiversas línguas portuguesas, ou diversas modalidades dessa mesma língua: há a língua formal, ou forma culta da língua, há a língua coloquial, há os dialetos, e assim por diante.

2. a - A língua é uma produção social. "A língua é produzida socialmente. Sua produção ereprodução éfato cotidiano, localizado no tempo eno espaço da vida doshomens" (ALM EIDA, in GERALDI, O rg., 1997, p.14).

3. - - Como a língua é vista na escola? É o mesmo autor (ALM EIDA, in GERALDI, org. 1997) que afirma: "M uitas vezes a escola esquece que educação é um problema social" e, em decorrência disso, é comum vermos "muitos professores de português tragicamenteensinando análisesintática a crianças mal alimentadas" ( $p$. 16). É a escola, muitas vezes, apresentando-se eatuando completamente desigadada realidade social.

Esses três pontos destacados detantos outros problemas que surgem para 0 ensino e no ensino da língua portuguesa trazem de volta o contexto da pesquisa realizada. É com o enfoque de trêsitens dela, eque decerta forma se relacionam com as observações apontadas, que iremos concluir este texto.

1.- - H ouve, no Relatório apresentado, uma conclusão em queseafirmava: " $O$ professor deve adaptar-se à linguagem do aluno e, à medida que este mostra progressos no seu aprendizado, o professor pode, aos poucos, ir modificando sua linguagem para uma forma mais elaborada." H á que se levar em conta o que afirma POSSEN TI (in GERALDI, 1977, p. 33): “O objetivo da escola é ensinar o português padrão, ou, talvez, mais exatamente, o decriar condições para queele seja aprendido." D e fato, se o professor agir como se recomenda no Relatório, poderiam ser enfocados dois aspectos da língua: aquele do ambiente do próprio aluno, que ele já 
domina, eaquele outro a que deve al cançar quem aspira progredir nos estudos, em uma profissão e, conseqüentemente, na própria escala social. 0 aperfeiçoamento pessoal e a ascensão social, como meta, devem constituir um ideal de todos.

2.- - H á a necessidade de os professores compreenderem a origem e a função social da língua. O Relatório apontava: "É interessante mostrar o uso da linguagem em diferentes aspectos, pois o uso de certo tipo delinguagem pode não conferir com o meio. É bom saber discernir sobre essas variações de necessidade." Portanto, previa-se que os professores estivessem conscientizados dessa necessidade, pois só assim poderiam compreender a importância da adequação da linguagem ao ambiente social. Assim também os professores poderão saber como ir inserindo, paulatinamente, a linguagem elaborada, ou seja, o padrão culto da língua. N esse trabal ho, as metodologias deensino, a seleção de textose o trabalho do professor junto aosalunos se tornam imprescindíveis para a melhoria do conhecimento e do uso da língua portuguesa. O s contínuos exercícios da língua viva, com exemplos extraídos da própria realidade do aluno, podem contribuir para a melhoria do ensino da língua portugue sa, aperfeiçoamento esse que é necessário, que a comunidade escolar deseja e que algum dia, temos a esperança, deverá tornar-se realidade em nosso país.

3.- - A escolha dos conteúdosa serem ensinados é ponto fundamental em qualquer planejamento pedagógico. D eve-se ensinar aquilo de que os alunos realmente necessitam. D aí ser mais apropriado ensinar uma língua que realmente seja falada e não uma língua teórica, idealizada como modelo, distante da realidade vivida pelo aluno. H á que se considerar também que há uma modalidade delíngua que o aluno já domina, embora a seu modo. Portanto, há que ir buscando o contínuo aperfeiçoamento dessa forma de linguagem. 0 ensino da análise sintática referido de modo crítico por um dos autores citados tem sido continuamente condenado pela forma como esse ensino éfeito. G eralmente, não apresenta um objetivo claro. $\mathrm{N}$ ão se esclarece aquilo que se deseja ensinar com a prática da análise desenvolvida. Apresentam-se exemplos pré-elaborados, numa linguagem completamente afastada da linguagem de domínio do aluno. N esses casos, fica a análise sintática pela própria análise sintática. $\mathrm{N}$ a mai or parte das vezes, 0 aluno nem sabe o que está fazendo. 0 s exercícios se tornam mecânicos e repetitivos. A teoria quando é dada, trata-se mais de uma elocubração sobre a estrutura das frases do que propriamente o estudo da estrutura e do significado dessas frases, orações ou períodos. N esse sentido, sim, o seu ensino deve ser condenado. Seria muito mai sútil a prática da leitura, os exercícios de compreensão ede produção de um texto, do que uma pretensa análise de fragmentos desse mesmo texto. 0 Relatório ousou referirse à necessidade de se emprender uma pesquisa sociológica para uma escola "meIhor integrar-se com o meio em que atua. Essa análise consistiria em pesqui sa sobre as necessidades, cultura local e os objetivos dessa escola." 
Finalmente, o Relatório vislumbrava algumas ações que já vêm sendo colocadas em prática e apontava, como uma delas, A Escola para o Professor, em Faxinal do Céu, em nosso estado, como também uma fiscalização mais rigorosa da qualidade dos livros didáticos empreendida pelo M inistério da Educação. Apontava, porém: "O que falta a esses programas é uma maior abrangência."

A pesquisa e as sugestões apresentadas, como concluía o Relatório, tiveram "a intenção de transformar um ensino limitador e passivo em libertador e ativo." N ele, propunha-se e se defendia um modelo deensino dinâmico, quepossa produzir conhecimento etransformar a realidade, enão um ensino estático, meramente repetidor de conteúdos nem sempre adequados à realidade da escola e à vivência e aos interesses do aluno.

\section{Referências bibliográficas de autores citados ou referidos}

ALM EID A, M. . . de. Ensinar português?, In GERALDI, J. W. (O rg.). 0 texto na sala de aula. São Paulo: Ática, 1997 (Col. N a sala de aula).

BAN D EIRA, Grace dos Anjos Freire. 0 ensino da língua portuguesa com o conhecimento do latim: uma análise dos fatores de textualidade em livros didáticos. D issertação de mestrado. Curitiba: PU CPR, 1996.

BART H ES, R. Elementos de semiologia. 5. ed. São Paulo: Cultrix, 1977.

BUEN O, J. F. Produzir um bom texto: tarefa possível no ensino superior, in: D iálogo educacional, n.2. Curitiba: PU CPR, Programa de Pós-Graduação em Educação, jul./dez. 2000, p.35-9.

BUEN O , J. F. Linguagem e educação, in: C adernos de resultados do VII Encontro de Iniciação Científica PIBIC/C N Pq. Curitiba: PU CPR, 1999.

BUFFON. D iscours sur le style, in: LAN SO N, G. e TUFFRAU, P. M anuel Illustréd"histoire de la littérature françaisedes originesal'époquecontemporaine. Paris: H achette, 1953.

CAVALCANTI, I. A. C. A prática pedagógica inovadora e a poesia como um elemento articulador no ensino da língua portuguesa no $C$ urso de Pedagogia. D issertação de mestrado. Curitiba: PU CPR, 2000.

CH IARELO , I. S. A leitura e o ensino com pesquisa no curso superior: uma proposta de aprender a aprender. Dissertação de mestrado. Curitiba: PU CPR, 2000. 
COSTA, M . M . A leitura docente na Pontifícia Universidade C atólica do Para ná. Projeto de pesquisa. Curitiba: PU CPR, 2001.

FERN AN DEZ, L. B. C. Arte-educação na produção de texto crítico e criativo no ensino superior. Dissertação de mestrado. Curitiba: PU CPR, 2001.

FREIRE, M.T. M. A prática pedagógica e a língua inglesa na formação universitária do profissional de Relações Públicas. Dissertação de mestrado. Curitiba: PU CPR, 1998.

GERALDI, J. W. (O rg.). 0 texto na sala de aula. São Paulo: Ática, 1997. (Col. Na Sala de Aula).

POSSENTI, S. Sobreo ensino deportuguêsna escola, in: GERALDI, J.W. (O rg.). 0 texto na sala de aula. São Paulo: Ática, 1997. (Col. N a Sala de Aula).

PRIG O GINE, I. 0 fim das certezas. São Paulo: Afiliada, 1996.

RICOEUR, P. 0 discurso da ação. Lisboa: Edições 70, 1988.

SILVA, E. F. deS. A nova proposta educacional da PU C PR : uma reflexão sobre a prática docente e os programas de aprendizagem no $C$ urso de Letras Português/ Inglês. Projeto de pesquisa. Curitiba: PU CPR, 2001.

VILAS-BOAS, M . C. 0 ensino com pesquisa como metodologia da prática pedagógica: um estudo realizado no Curso de Secretariado Executivo da PU CPR. D issertação de mestrado. Curitiba: PU CPR, 1999.

Recebido em: 22/10/2001

Aprovado em: 12/11/2001 